\title{
OPEN One-step electrodeposition of a polypyrrole/NiO nanocomposite as a supercapacitor electrode
}

\begin{abstract}
Jehan El Nady ${ }^{1}$, Azza Shokry², Marwa Khalil ${ }^{3}$, S. Ebrahim² ${ }^{2}$ A. M. Elshaer ${ }^{4}$ \& M. Anas $^{5}$
An electrochemical deposition technique was used to fabricate polypyrrole (Ppy)/NiO nanocomposite electrodes for supercapacitors. The nanocomposite electrodes were characterized and investigated by Fourier transform infrared spectroscopy (FTIR), X-ray Diffraction (XRD), scanning electron microscopy (SEM), cyclic voltammetry (CV), galvanostatic charge-discharge (GCD) and electrochemical impedance spectroscopy (EIS). The performance of supercapacitor electrodes of Ppy/NiO nanocomposite was enhanced compared with pristine Ppy electrode. It was found that the Ppy/NiO electrode electrodeposited at $4 \mathrm{~A} / \mathrm{cm}^{-2}$ demonstrated the highest specific capacitance of $679 \mathrm{Fg}^{-1}$ at $1 \mathrm{Ag}^{-1}$ with an energy density of $94.4 \mathrm{Wh} \mathrm{kg}^{-1}$ and power density of $500.74 \mathrm{~W} \mathrm{~kg}^{-1}$. Capacitance retention of $83.9 \%$ of its initial capacitance after 1000 cycles at $1 \mathrm{Ag}^{-1}$ was obtained. The high electrochemical performance of $\mathrm{Ppy} / \mathrm{NiO}$ was due to the synergistic effect of $\mathrm{NiO}$ and $\mathrm{Ppy}$, where a rich pores networklike structure made the electrolyte ions more easily accessible for Faradic reactions. This work provided a simple approach for preparing organic-inorganic composite materials as high-performance electrode materials for electrochemical supercapacitors.
\end{abstract}

Supercapacitors, as storage devices, play a main role in bridging the gap between conventional capacitors and batteries ${ }^{1}$. Conducting polymers can be used as electrodes to compensate for the low energy density of carbon structures because of their highly reversible oxidation-reduction, pseudocapacitance and high electrical conductivity $^{2,3}$. The pseudosupercapacitor is of interest due to its high power and energy density. Ppy, polyvinylcarbazole, polythiophene, polyazulene and polyaniline have been applied as electrodes for pseudocapacitors. Ppy has many advantages where its pyrrole monomer is easily oxidized and soluble in water, and Ppy has a reversible electrochemical doping/dedoping process ${ }^{4-6}$.

The fabrication of Ppy electrodes by electropolymerization of pyrrole is an interesting technique that allows pyrrole and certain dopants to be oxidized at the electrode surface by applying an anodic potential or a current or potentiodynamic window (cyclic voltammetry) to form a polymer film ${ }^{7}$. The dopant is inserted during Ppy formation to confirm the electrical neutrality of the produced film. Different works have focused on the modification of Ppy, optimization of film deposition conditions, and development of dopants ${ }^{8,9}$. High electrical conductivity and thermal stability of Ppy films were obtained using aromatic anionic dopants. The electrical and electrochemical properties were modified and controlled using certain functionalized dopants, such as p-toluene sulfonate, anthraquinone-2-sulfonate and benzene sulfonate ${ }^{10}$. However, Ppy undergoes deformation during cyclic voltammetry and charge-discharge, which leads to a reduction in cyclic stability. To enhance the stability of Ppy, composites with hierarchical structured nanomaterials reduce the volume change of Ppy during charge-discharge ${ }^{11}$. In addition, different transition metal oxides can be considered as electrodes pseudocapacitor behavior ${ }^{12,13}$. Compared with the electrode materials based on carbon derivatives or conducting polymers,

\footnotetext{
${ }^{1}$ Electronic Materials Department, Advanced Technology and New Materials Research Institute, City of Scientific Research and Technological Applications (SRTA-City), P.O. Box 21934, New Borg El-Arab City, Alexandria, Egypt. ${ }^{2}$ Department of Materials Science, Institute of Graduate Studies and Research, Alexandria University, 163 Horrya Avenue, P.O. Box832, El-Shatby, Alexandria, Egypt. ${ }^{3}$ Nanotechnology and Composite Materials Department, Advanced Technology and New Materials Research Institute, City of Scientific Research and Technological Applications (SRTA-City), P.O. Box 21934, New Borg El Arab City, Alexandria, Egypt. ${ }^{4}$ Department of Computer Engineering, Higher Institute of Engineering and Technology, P.O. Box 22751, El-Boheira, Egypt. ${ }^{5}$ Physics Department, Faculty of Science, Alexandria University, Moharram Bek, Alexandria 21511, Egypt. ${ }^{\bowtie}$ email: j.elnady@gmail.com
} 
transition metal oxides (TMOs) possess the advantage of higher capacitances in practice ${ }^{14-16}$. NiO is a promising pseudocapacitive electrode due to its high capacity and stability. On the other hand, the performance of $\mathrm{NiO}$ electrodes is poor due to their low conductivity ${ }^{17,18}$. In this study, a new nanocomposite of Ppy/NiO electrodes were fabricated via one-step facile electrochemical deposition method at different currents onto the surface of graphite sheet. The electrochemical behavior of the as-prepared electrodes was investigated by cyclic voltammetry (CV), galvanostatic charge-discharge (GCD) and electrochemical impedance spectroscopy (EIS).

\section{Method}

Materials. Pyrrole monomer (Py, 98\%) was obtained from Sigma-Aldrich, Germany. Nickel sulfate $\left(\mathrm{NiSO}_{4}\right)$ and nickel chloride $\left(\mathrm{NiCl}_{2}\right)$ were purchased from LOBAL Chemie, Mumbai, India. Boric acid $\left(\mathrm{H}_{3} \mathrm{BO}_{3}\right)$ and lithium perchlorate $\left(\mathrm{LiClO}_{4}\right)$ were received from local chemical companies. A graphite sheet (GS) and platinum rod (Pt) was purchased from Shanghai Phoenix Alloy Co., China. Hydrochloric acid (34\%) and ethanol (99.8\%) were obtained from Alfa Aesar and J. T. Baker, respectively. Dodecylbenzene sulfonic acid (DBSA, $\left.\mathrm{C}_{18} \mathrm{H}_{30} \mathrm{O}_{3} \mathrm{~S}\right)$ was received from El-Gomhoria Chemical Company, Egypt. All chemicals were used without further purification.

Preparation of Ppy ${ }_{1 \%}-\mathrm{DBSA}_{\mathbf{2}} / \mathrm{NiO}_{\mathbf{9 7} \%}$-GS supercapacitor electrodes. $\quad \mathrm{Ppy}_{1 \%}-\mathrm{DBSA}_{2 \%} / \mathrm{NiO}_{97 \%}-\mathrm{GS}$ supercapacitor electrodes were synthesized by electrochemical deposition using nickel sulfate, nickel chloride, and boric acid as precursors for NiO formation and DBSA and Py as sources of doped Ppy. Typically, $15.5 \mathrm{~g}$ of $\mathrm{NiSO}_{4}, 2.5 \mathrm{~g}$ of $\mathrm{NiCl}_{2}$, and $2 \mathrm{~g}$ of $\mathrm{H}_{3} \mathrm{BO}_{3}$ were dissolved in $50 \mathrm{~mL}$ deionized water with stirring for $1 \mathrm{~h}$ to form a foam light green solution. Then, $1 \mathrm{~mL}$ Py and $2 \mathrm{~mL}$ DBSA were added to the light green solution and stirred for $1 \mathrm{~h}$ at room temperature until a heavily green solution appeared. The electrochemical deposition supercapacitor (SC) electrodes were synthesized using an electrochemical OrigaFlex-OGF05 (Origalys, France) workstation with different currents using a three-electrode cell configuration at room temperature. The three electrode cell contains a $4.0 \times 1.5 \mathrm{~cm}^{2} \mathrm{Pt}$ sheet as a counter electrode and $\mathrm{Ag} / \mathrm{AgCl}$ as a reference electrode. The GS substate was cut into rectangular shapes with dimensions of $4.5 \times 1 \times 0.3 \mathrm{~cm}^{3}$ as a current collector. The Ppy ${ }_{1 \%}-\mathrm{DBSA}_{2 \%} /$ $\mathrm{NiO}_{97 \%}$-GS electrode was synthesized by depositing a thin layer using chronopotentiometry at current densities of 2, 4, 6, 8, and $10 \mathrm{~mA} \mathrm{~cm}{ }^{-2}$ for $10 \mathrm{~min}$. The SC electrodes prepared at various currents of 2, 4, 6, 8, and $10 \mathrm{~mA} \mathrm{~cm}{ }^{-2}$ were coded as Ppy P $_{1 \%}-\mathrm{DBSA}_{2 \%} / \mathrm{NiO}_{97 \%}$-GS@2, Ppy ${ }_{1 \%}-\mathrm{DBSA}_{2 \%} / \mathrm{NiO}_{97 \%}-\mathrm{GS} @ 4, \mathrm{Ppy}_{1 \%}-\mathrm{DBSA}_{2 \%} /$ $\mathrm{NiO}_{97 \%}$-GS@6, $\mathrm{Ppy}_{1 \%}-\mathrm{DBSA}_{2 \%} / \mathrm{NiO}_{97 \%}-\mathrm{GS} @ 8$, and $\mathrm{Ppy}_{1 \%}-\mathrm{DBSA}_{2 \%} / \mathrm{NiO}_{97 \%}$-GS@10, respectively. The fabricated $\mathrm{SC}$ electrodes were rinsed with deionized water and dried at $60^{\circ} \mathrm{C}$.

Characterization. The composition of the prepared $\mathrm{Ppy}_{1 \%}-\mathrm{DBSA}_{2 \%} / \mathrm{NiO}_{97 \%}$-GS supercapacitor electrode was studied using Fourier transform infrared (FTIR) (Bruker Corporation, Ettlingen, Germany). The crystalline structure of Ppy/NiO nanocomposite and PPy were studied by using X-ray diffraction was performed using (X-ray 7000 Shimadzu-Japan) at room temperature in the range of $2 \mathrm{~h}$ from $10^{\circ}$ to $100^{\circ}$. The X-ray source $\mathrm{Cu}$ target generated at $30 \mathrm{kV}$ and $30 \mathrm{~mA}$ with a scan speed of $4^{\circ} \mathrm{min}^{-1}$. The morphological properties of the prepared nanocomposite were investigated using scanning electron microscopy (SEM), JEOL (JSM 6360 LA, Japan) instruments. Galvanostatic electrochemical charge/discharge (GCD), cyclic voltammetry (CV) and electrochemical impedance spectroscopy (EIS) measurements were performed in a three electrode cell at room temperature using a computer-controlled potentiostat (Metrohm Autolab 87070, Germany). Pt and Ag/ AgCl electrodes were immersed in acetonitrile of $0.1 \mathrm{M} \mathrm{LiClO}_{4}$ electrolyte solution in the three electrode cell to characterize the fabricated $\mathrm{Ppy}_{1 \%}-\mathrm{DBSA}_{2 \%} / \mathrm{NiO}_{97 \%}$-GS SC electrodes. CV and GC/D were carried out for the fabricated SC electrodes in the potential window ranging from 0 to $1 \mathrm{~V}$ at sweep rates of $5,15,35,50,75$, and $100 \mathrm{mV} \mathrm{s}^{-1}$ and current densities from 1 to $3 \mathrm{Ag}^{-1}$. EIS was implemented in the frequency range from $100 \mathrm{kHz}$ to $0.01 \mathrm{~Hz}$ at $5 \mathrm{mV}$. Cyclic stability test was conducted at a current density of $1 \mathrm{Ag}^{-1}$ for 1000 cycles. Different performance parameters of the specific capacitance (Cs), energy density $(\mathrm{E})$ and power density $(\mathrm{P})$ of the prepared SC electrodes were calculated by the following equations ${ }^{19,20}$ :

$$
\begin{gathered}
C s=\frac{\int_{V i}^{V f} I(V) d V}{2 \mathrm{sm} \Delta \mathrm{V}} \\
\mathrm{Cs}=\frac{\mathrm{I} \times \mathrm{t}}{\mathrm{m} \times \Delta \mathrm{V}} \\
E=\frac{C s \times \Delta V^{2}}{2 \times 3600} \\
P=\frac{E \times 3600}{\Delta t}
\end{gathered}
$$

where I, $\mathrm{t}, \Delta \mathrm{V}$, s, and $\mathrm{m}$ are the discharge current (A), discharge time (s), discharge potential window $(\mathrm{V})$, scan rate $\left(\mathrm{V} \mathrm{s}^{-1}\right)$ and mass of the active material $(\mathrm{g})$, respectively.

\section{Results and discussion}

Electropolymerization of $\mathrm{Ppy}_{1 \%}-\mathrm{DBSA}_{2 \%} / \mathrm{NiO}_{97 \%}-\mathrm{GS}$. Figure 1 shows the potential-time curves of the chronopotentiometry processes of the synthesis of $\mathrm{Ppy}_{1 \%}-\mathrm{DBSA}_{2 \%} / \mathrm{NiO}_{97 \%}$-GS with different current densities from 2 to $10 \mathrm{~mA} \mathrm{~cm}$-2 for $600 \mathrm{~s}$. The electropolymerization process usually consists of three stages, as 


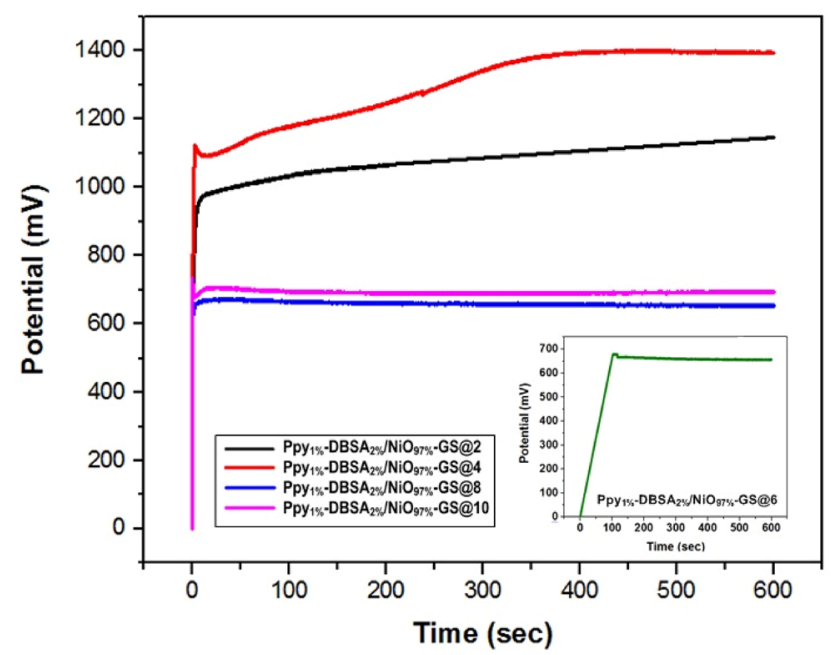

Figure 1. Potential versus time curves of the chronopotentiometry processes of $\mathrm{Ppy}_{1 \%}-\mathrm{DBSA}_{2 \%} / \mathrm{NiO}_{97 \%}-\mathrm{GS}$ at different current densities from 2 to $10 \mathrm{~mA} \mathrm{~cm}^{-2}$.

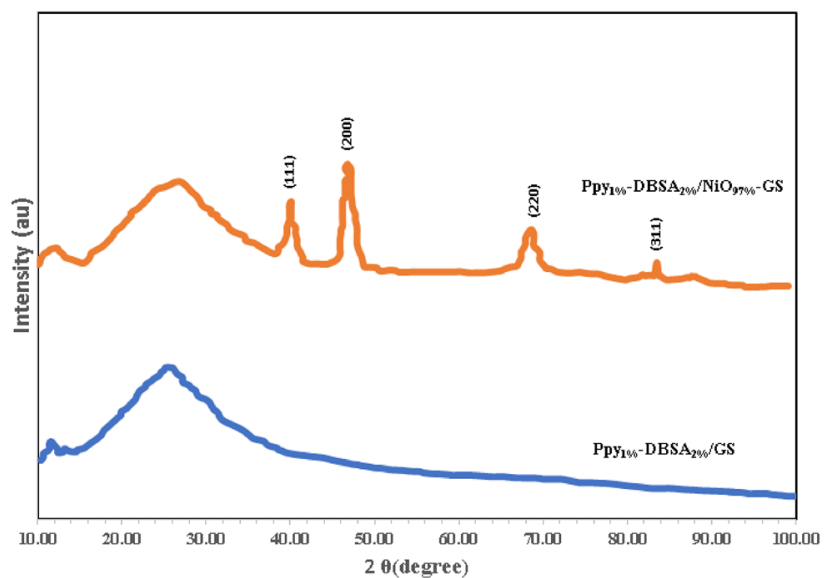

Figure 2. XRD patterns of pure $\mathrm{Ppy}_{1 \%}-\mathrm{DBSA}_{2 \%} / \mathrm{GS}$ and $\mathrm{Ppy}_{1 \%}-\mathrm{DBSA}_{2 \%} / \mathrm{NiO}_{97 \%}-\mathrm{GS}$.

reported in the literature ${ }^{21-23}$. At the beginning of electropolymerization deposition, the voltage suddenly increases after application of different current densities due to the cathodic overpotential between Pt as a counter and GS as a working electrode. The maximum potentials recorded in the voltage-time curves of the prepared $\mathrm{Ppy}_{1 \%}-\mathrm{DBSA}_{2 \%} / \mathrm{NiO}_{97 \%}$-GS film at 2, 4, 6, 8, and $10 \mathrm{~mA} \mathrm{~cm}{ }^{-2}$ are $1045,1350,678,680$, and $717 \mathrm{mV}$, respectively. For 2 and $4 \mathrm{~mA} \mathrm{~cm}^{-2}$ the voltage increases to the supersaturation region with time due to the increases in the number of charge carriers and the critical grain size or the formation of oligomers of the $\mathrm{Ppy}_{1 \%}-\mathrm{DBSA}_{2 \%} / \mathrm{NiO}_{97 \%}-$ GS deposited on the GS electrode. This can be explained based on the first few seconds of the applied current is sufficient to form the radical cations on the pyrrole rings and start the propagation step in the stage of growth. The potential needs for the formation of radicals from the dimer or trimer is lower than that required to form the pyrrole radicals. Consequently, the potential is lower again after few seconds and attain to the plateau regions. Moreover, the temporary decays appear as a small valley in the voltage curves at 6,8 , and $10 \mathrm{~mA} \mathrm{~cm}^{-2}$, which correspond to the diffusion limitation of the oxidation process on the Py monomer, and then small peaks appear after the valley is revealed to the nucleation end growth of the $\mathrm{Ppy}^{21,22}$. It is noted that at $2 \mathrm{~mA} \mathrm{~cm}^{-2}$, the saturation potential is about $1000 \mathrm{mV}$ and with increasing the current density to $4 \mathrm{~mA} \mathrm{~cm}^{-1}$ the saturation potential is raised to about $1200 \mathrm{mV}$. This indicates the formation of the DBSA doped Ppy film, which is more conductive than the GS substrate However, at 8 and $10 \mathrm{~mA} \mathrm{~cm}^{-2}$ the plateau region is declined to 700 and $750 \mathrm{mV}$, respectively and this is attributed to the degradation of the polymeric films at high current density.

Structural analysis of $\mathrm{Ppy}_{1 \%}-\mathrm{DBSA}_{\mathbf{2}} / \mathrm{NiO}_{\mathbf{9 7} \%}$-GS film. The XRD patterns of pristine $\mathrm{Ppy}_{1 \%}-\mathrm{DBSA}_{2 \%} /$ GS and $\mathrm{Ppy}_{1 \%}-\mathrm{DBSA}_{2 \%} / \mathrm{NiO}_{97 \%}$-GS electrodes are shown in Fig. 2. The XRD pattern of pure $\mathrm{Ppy}_{1 \%}-\mathrm{DBSA}_{2 \%} / \mathrm{GS}$ displays a broad peak at $2 \theta=25.20^{\circ 24}$. The XRD pattern of the $\mathrm{Ppy}_{1 \%}-\mathrm{DBSA}_{2 \%} / \mathrm{NiO}_{97 \%}-\mathrm{GS}$ shows all the characteristic sharp peaks of a cubic phase of $\mathrm{NiO}$ (JCPDS: $47-1049)^{25-28}$. The characteristic peaks at $2 \theta=39.50^{\circ}, 46.80^{\circ}$, 


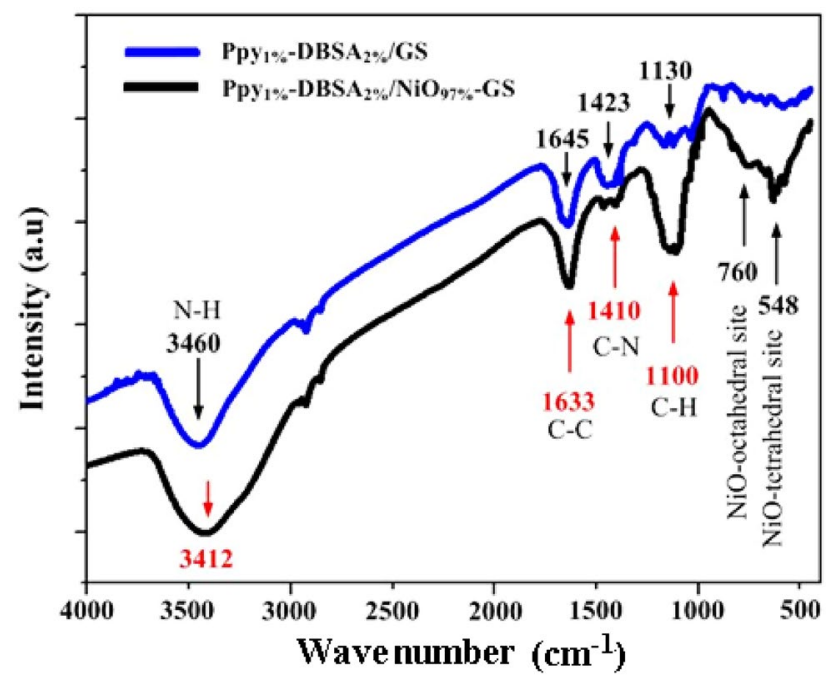

Figure 3. FTIR spectra of pure $\mathrm{Ppy}_{1 \%}-\mathrm{DBSA}_{2 \%} / \mathrm{GS}$ and $\mathrm{Ppy}_{1 \%}-\mathrm{DBSA}_{2 \%} / \mathrm{NiO}_{97 \%}-\mathrm{GS}$.

$68.60^{\circ}$ and $83.50^{\circ}$ can be indexed to (111), (200), (220), (311) and (222) diffraction planes of NiO, respectively ${ }^{29,30}$. The XRD pattern represents the formation of $\mathrm{NiO} / \mathrm{PPy}$ composite with good crystal phase.

Figure 3 presents the FTIR spectra of pure $\mathrm{Ppy}_{1 \%}-\mathrm{DBSA}_{2 \%} / \mathrm{GS}$ and $\mathrm{Ppy}_{1 \%}-\mathrm{DBSA}_{2 \%} / \mathrm{NiO}_{97 \%}-\mathrm{GS}$ in the range of $400-4000 \mathrm{~cm}^{-1}$. A broad band at approximately $3460 \mathrm{~cm}^{-1}$ is attributed to $\mathrm{N}-\mathrm{H}$ stretching associated with the bound pyrrole ring ${ }^{24}$. The peaks at 1645,1423 , and $1130 \mathrm{~cm}^{-1}$ are assigned to the $\mathrm{C}-\mathrm{C}$ and $\mathrm{C}-\mathrm{N}$ stretching vibrations and the $\mathrm{C}-\mathrm{H}$ in-plane vibrational bands of the polypyrrole ring, respectively ${ }^{25}$. These results indicate that Ppy has been formed. In the $\mathrm{Ppy}_{1 \%}-\mathrm{DBSA}_{2 \%} / \mathrm{NiO}_{97 \%}$-GS sample, the observed absorption bands at 760 and $548 \mathrm{~cm}^{-1}$ are corresponded to the torsional and stretching vibration modes of the $\mathrm{NiO}$ bond at the octahedral and tetrahedral sites, respectively ${ }^{26,27}$. Most of the stretching vibrations in the $\mathrm{Ppy}_{1 \%}-\mathrm{DBSA}_{2 \%} / \mathrm{NiO}_{97 \%}-\mathrm{GS}$ sample are the same as that of PPy, with only a slight shift of IR absorption to lower frequencies in $\mathrm{Ppy}_{1 \%}-\mathrm{DBSA}_{2 \%} / \mathrm{NiO}_{97 \%}$ GS to $3414,1633,1410$, and $1100 \mathrm{~cm}^{-1}$, respectively. This suggests that an interaction between the polymer and $\mathrm{NiO}$ occurs. This change is due to loss in conjugation and molecular order after modification of Ppy with $\mathrm{NiO}$. This result indicates a strong interaction between $\mathrm{Ppy}$ and $\mathrm{NiO}$ nanoparticles ${ }^{28,29}$.

Surface morphology analysis. SEM micrographs of the electrochemically prepared pure $\mathrm{Ppy}_{1 \%}-\mathrm{DBSA}_{2 \%} /$ GS film are illustrated in Fig. 4a. The electronic properties of polypyrrole films are linked to their morphology; the smoother and denser surface leads to a conductive film, and the more pores and ordered film facilitates charge transfer through the film. Ppy films show a cauliflower-like nodular surface morphology and microspherical grains of approximately less than $1 \mu \mathrm{m}$ diameter. The effect of current densities and $\mathrm{NiO}$ on the microstructure of Ppy is indicated in Fig. 4b-e. There are a number of faceted grains elongated and rectangular blocks with different dimensions observed. These blocks result from the formation of $\mathrm{NiO}$, as shown in Fig. $4 \mathrm{~b}$. Increasing the current density to $4 \mathrm{~mA} \mathrm{~cm} \mathrm{~cm}^{-2}$ for prepared in situ Ppy and $\mathrm{NiO}$, as presented in Fig. $4 \mathrm{c}$, drives to fusion of the cauliflower and rectangular structures and formation of pores, voids and compatible phases. The rich pores likestructure facilitates the diffusion and transfer of ions from the electrolyte to the electrode film and vice versa. On the other hand, for $\mathrm{Ppy}_{1 \%}-\mathrm{DBSA}_{2 \%} / \mathrm{NiO}_{97 \%}$-GS@6 displayed in Fig. 4d, the increasing of the current to $6 \mathrm{~mA}$ results in a higher thickness of the nanocomposite and induce the phase separation between PPy and NiO. For this composite, some of the rectangular blocks are converted to long rods. For $\mathrm{PPy}_{1 \%}-\mathrm{DBSA}_{2 \%} / \mathrm{NiO}_{97 \%}-\mathrm{GS} @ 8$, the dominant phase is a cauliflower-like structure of PPy. Finally, at $10 \mathrm{~mA}$ for electrodeposition of the nanocomposite electrode of $\mathrm{PPy} / \mathrm{NiO}$, graded stairs layers are obtained, as illustrated in Fig. 4f.

Electrochemical Properties of Ppy/NiO electrodes. The CV measurements for pure $\mathrm{Ppy}_{1 \%}-\mathrm{DBSA}_{2 \%} /$ GS and $\mathrm{Ppy}_{1 \%}$-DBSA $2 \% / \mathrm{NiO}_{97 \%}$-GS electroplated electroplated with current densities in $0.1 \mathrm{M} \mathrm{LiClO}_{4}$ electrolyte solution and at different scan rates are displayed in Fig. 5. CV curves of pristine $\mathrm{Ppy}_{1 \%}-\mathrm{DBSA}_{2 \%} / \mathrm{GS}$ (shown in Fig. 5a) at different scan rates ranging from 5 to $100 \mathrm{mV} \mathrm{s}^{-1}$ exhibit nearly rectangular shapes symmetrical across the zero current axis, and they do not appear to be oxidation-reduction peaks ${ }^{31,32}$, showing the typical characteristic of electrical double layer capacitance ${ }^{33,34}$. It is observed that the initial or start point of CV cycle toward anodic direction is not the same the end or final point during reversed in the cathodic direction. This can be explained based on the irreversibility of oxidation reduction reaction or due to effect of high scan rate. The current density of $\mathrm{Ppy}_{1 \%}$ - $\mathrm{DBSA}_{2 \%} / \mathrm{NiO}_{97 \%}$-GS supercapacitor electrode is directly proportional to scan rate. After the incorporation of $\mathrm{NiO}_{97 \%}$ into $\mathrm{Ppy}_{1 \%}-\mathrm{DBSA}_{2 \%} / \mathrm{GS}$ at different electroplating current densities, as shown in Fig. 5b, the integrated area of the CV curves of the electroplated electrode significantly increases due to the high pseudocapacitance originating from $\mathrm{NiO}$, high specific surface area, and abundant redox active sites generated by the porous $\mathrm{NiO}$ network ${ }^{33,35}$. The $\mathrm{CV}$ curves have a large enclosed area and good symmetrical rectangular shape, showing that the capacitive behavior of the electrode could be greatly improved by optimizing the electro- 

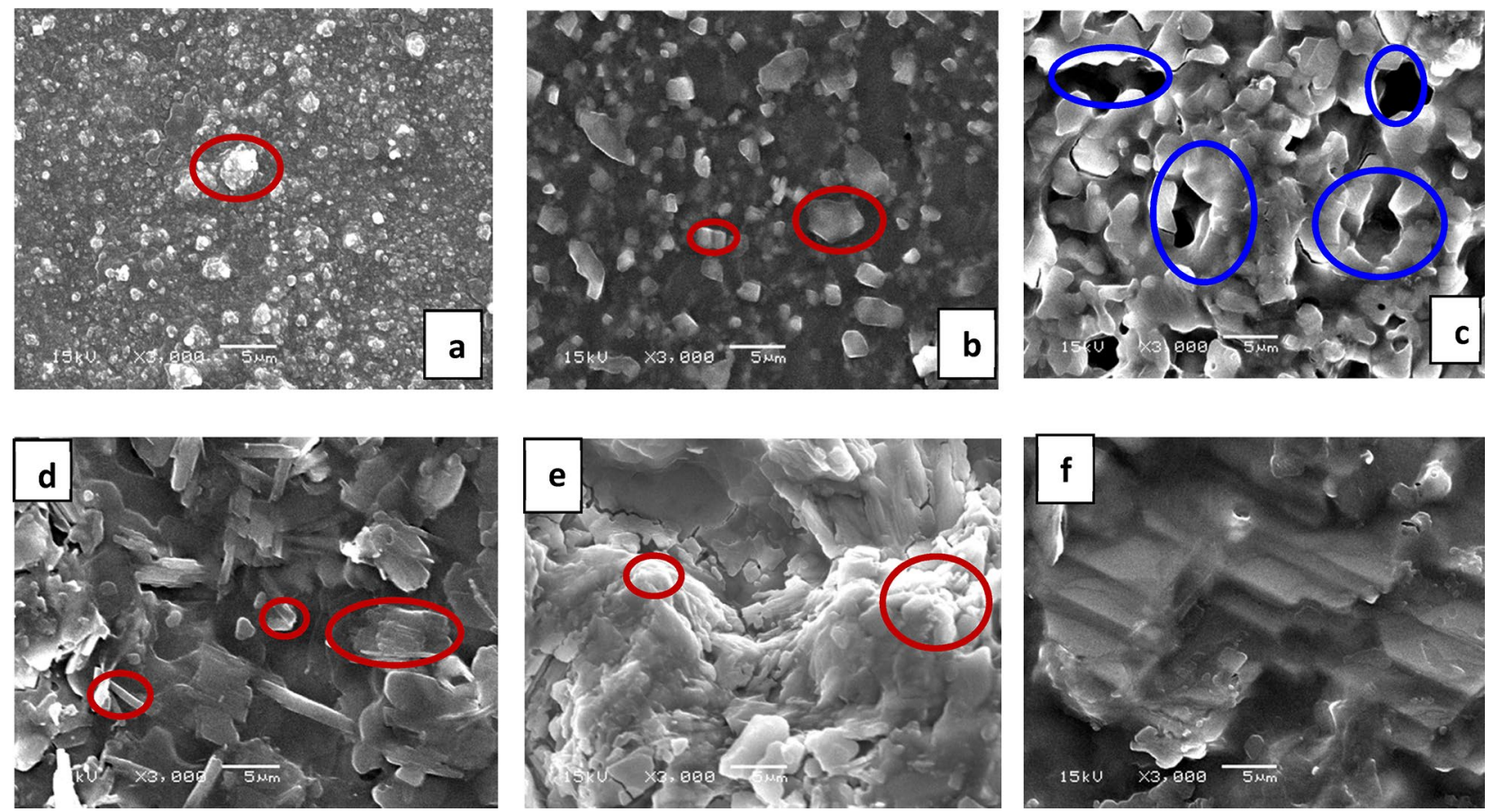

Figure 4. SEM images of (a) pure $\mathrm{Ppy}_{1 \%}-\mathrm{DBSA}_{2 \%} / \mathrm{GS}$, (b) $\mathrm{Ppy}_{1 \%}-\mathrm{DBSA}_{2 \%} / \mathrm{NiO}_{97 \%}-\mathrm{GS} @ 2$, (c) $\mathrm{Ppy}_{1 \%}-\mathrm{DBSA}_{2 \%} /$ $\mathrm{NiO}_{97 \%}-\mathrm{GS} @ 4$, (d) $\mathrm{Ppy}_{1 \%}-\mathrm{DBSA}_{2 \%} / \mathrm{NiO}_{97 \%}$-GS@6, (e) $\mathrm{Ppy}_{1 \%}-\mathrm{DBSA}_{2 \%} / \mathrm{NiO}_{97 \%}-\mathrm{GS} @ 8$, and (f) $\mathrm{Ppy}_{1 \%}-\mathrm{DBSA}_{2 \%} /$ $\mathrm{NiO}_{97 \%}-\mathrm{GS} @ 10$.

deposition current of the $\mathrm{Ppy}_{1 \%}-\mathrm{DBSA}_{2 \%} / \mathrm{NiO}_{97 \%}$-GS composite. The $\mathrm{Ppy}_{1 \%}-\mathrm{DBSA}_{2 \%} / \mathrm{NiO}_{97 \%}$-GS@4 supercapacitor electrode produces the maximum enclosed area. The CV curves of the $\mathrm{Ppy}_{1 \%}-\mathrm{DBSA}_{2 \%} / \mathrm{NiO}_{97 \%}-\mathrm{GS} \mathrm{Q}$ supercapacitor electrode at various scan rates from 5 to $100 \mathrm{mV} \mathrm{s}^{-1}$ are displayed in Fig. $5 \mathrm{c}$. A quasi-rectangular shape with no distortion appears in the CV curves. In addition, the current densities linearly increase with increasing scan rates, which may be attributed to the confirmation of the formation of efficient electrical double layers and fast charge propagation within the electrodes ${ }^{36}$.

The GCD curves of pure $\mathrm{Ppy}_{1 \%}-\mathrm{DBSA}_{2 \%} / \mathrm{GS}$ and $\mathrm{Ppy}_{1 \%}-\mathrm{DBSA}_{2 \%} / \mathrm{NiO}_{97 \%}$-GS supercapacitor electrodes prepared with different current densities and measured at $1 \mathrm{~A} / \mathrm{g}$ are presented in Fig. 6a. It is noted that symmetric triangular curves for fabricated supercapacitor electrodes and low charge-transfer resistances during charging and discharging even at high current densities with very little ohmic drop are obtained, indicating a high rate of their performance ${ }^{37}$. It is also found that the discharge time of the $\mathrm{Ppy}_{1 \%}-\mathrm{DBSA}_{2 \%} / \mathrm{NiO}_{97 \%}$-GS@4 supercapacitor electrode is the highest among the other electrodes prepared with different current densities. Consequently, the GCD curves for $\mathrm{Ppy}_{1 \%}-\mathrm{DBSA}_{2 \%} / \mathrm{NiO}_{97 \%}-\mathrm{GS} @ 4$ at 1.0, 2.0 and $3.0 \mathrm{~A} \mathrm{~g}^{-1}$ are shown in Fig. 6b, through which good linear potential-time profiles are achieved, demonstrating the good capacitance performance of this electrode. The specific capacitances are found to be $679,333.5$ and $292.7 \mathrm{~F} \mathrm{~g}^{-1}$ at 1,2 and $3 \mathrm{~A} \mathrm{~g}^{-1}$, respectively, showing the rate capability of the synthesized sample Ppy ${ }_{1 \%}-\mathrm{DBSA}_{2 \%} / \mathrm{NiO}_{97 \%}-\mathrm{GS} @ 4^{38}$. Using Eqs. (3) and (4), the energy density of $94.4 \mathrm{Wh} \mathrm{kg}^{-1}$ and power density of $500.74 \mathrm{~W} \mathrm{~kg}^{-1}$ are obtained for the highest capacitance sample, Ppy1\%-DBSA2\%/NiO97\%-GS@4 and this considers large values compared with other Ppy/NiO supercapacitors electrodes in the literatures ${ }^{16,24,25,40,41}$. The denser and more compact structure may have prevented cations from migrating into the electrode material ${ }^{39}$. For this reason, the specific capacitance of the composites first increases and then decreases with increasing Ppy/NiO film thickness ${ }^{40}$. Ppy ${ }_{1 \%}-\mathrm{DBSA}_{2 \%} / \mathrm{NiO}_{97 \%}-\mathrm{GS} @ 4\left(679 \mathrm{Fg}^{-1}\right)$ shows the highest performance compared with the other composites due to its high porosity, as observed in the SEM image (Fig. 4c). This provides paths to diffuse electrolyte ions into the hybrid arrays and enhances the Faradaic reactions ${ }^{41}$. $\mathrm{Ppy}_{1 \%}-\mathrm{DBSA}_{2 \%} / \mathrm{NiO}_{97 \%}$-GS@10 $\left(170 \mathrm{~F} \mathrm{~g}^{-1}\right)$ exhibits the smallest value of the specific capacitance, as shown in Fig. 6a, which is in good agreement with the CV results. The specific capacitance of $\mathrm{Ppy}_{1 \%}-\mathrm{DBSA}_{2 \%} /$ $\mathrm{NiO}_{97 \%}$-GS@4 is larger than that of pure PPy $\left(456 \mathrm{~F} \mathrm{~g}^{-1}\right)$, and this is attributed to the synergistic effect of $\mathrm{NiO}$ and Ppy. The embedment of $\mathrm{NiO}$ as a molecular level dispersion in the Ppy matrix can reduce electron shuttling along the conjugated chains by interlinking the Ppy chains, leading to the enhancement of the overall conductivity of $\mathrm{NiO} / \mathrm{PPy}^{39}$.

The specific capacitance (Csp) was calculated from the CV curves by integrating the area under the CV curve using Eq. (1). As shown in Fig. 7a, Ppy $1 \%-\mathrm{DBSA}_{2 \%} / \mathrm{NiO}_{97 \%}$-GS@4 has larger Csp values than $\mathrm{Ppy}_{1 \%}-\mathrm{DBSA}_{2 \%} / \mathrm{GS}$ at different scan rates from 5 to $100 \mathrm{mV} \mathrm{s}^{-1}$. The Csp value of $\mathrm{Ppy}_{1 \%}-\mathrm{DBSA}_{2 \%} / \mathrm{NiO}_{97 \%}-\mathrm{GS} @ 4$ at $5 \mathrm{mV} \mathrm{s}^{-1}$ is calculated to be $605 \mathrm{~F} \mathrm{~g}^{-1}$ and is higher than the value of $364 \mathrm{~F} \mathrm{~g}^{-1}$ for $\mathrm{Ppy}_{1 \%}-\mathrm{DBSA}_{2 \%} / \mathrm{GS}$ at the same scan rate. The dependence of Csp on scan rate exhibits a decay of 35\% Csp of $\mathrm{Ppy}_{1 \%}-\mathrm{DBSA}_{2 \%} / \mathrm{NiO}_{97 \%} \mathrm{GS} @ 4$ with increasing scan rate from 5 to $100 \mathrm{mV} \mathrm{s}^{-1}$. The area under the $\mathrm{CV}$ curves increases. It is noted that the shape of CVs at different scan rates is the same indicating the excellent rate capability and reversibility of the SC electrodes. At low scan rate, the electrolyte ions diffuse and migrate into active Ppy and high specific capacitances are produced. On the 

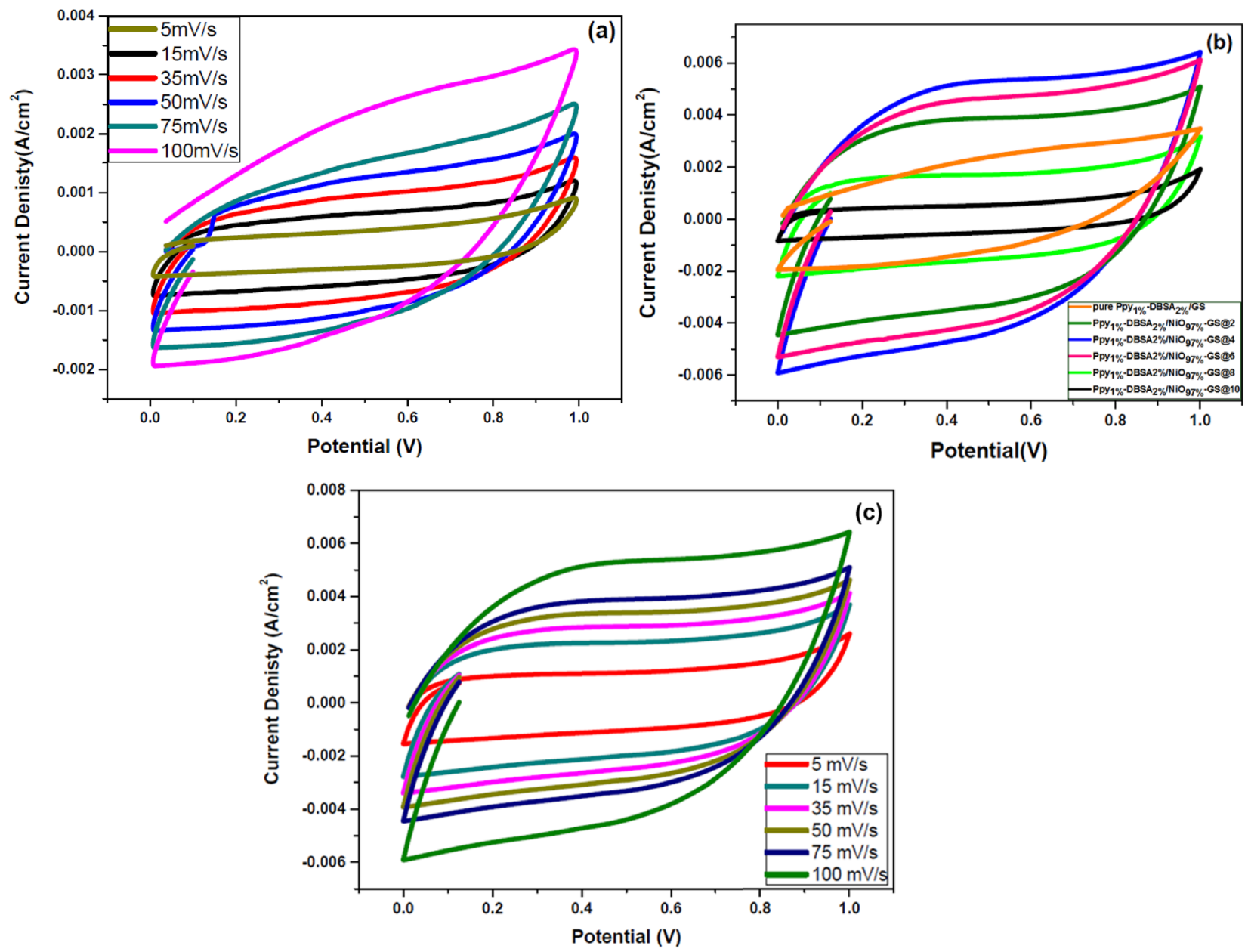

Figure 5. CV curves of (a) pure $\mathrm{Ppy}_{1 \%}-\mathrm{DBSA}_{2 \%} / \mathrm{GS}$ at different scan rates, (b) $\mathrm{Ppy}_{1 \%}-\mathrm{DBSA}_{2 \%} / \mathrm{GS}$ and $\mathrm{Ppy}_{1 \%}$ $\mathrm{DBSA}_{2 \%} / \mathrm{NiO}_{97 \%}$-GS nanocomposites at $100 \mathrm{mV} / \mathrm{s}$, and (c) $\mathrm{Ppy}_{1 \%}-\mathrm{DBSA}_{2 \%} / \mathrm{NiO}_{97 \%}-\mathrm{GS} @ 4$ at different scan rates.
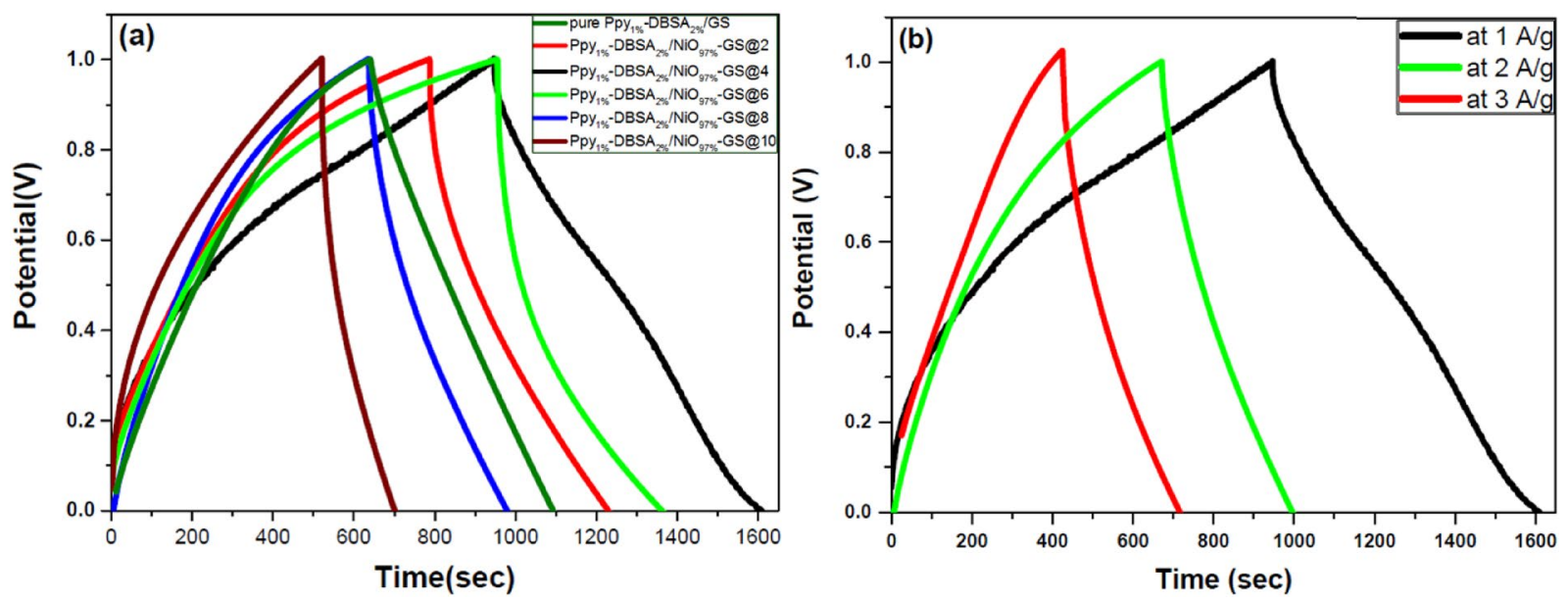

Figure 6. GCD curves of (a) pure $\mathrm{Ppy}_{1 \%}-\mathrm{DBSA}_{2 \%} / \mathrm{GS}$ and $\mathrm{Ppy}_{1 \%}-\mathrm{DBSA}_{2 \%} / \mathrm{NiO}_{97 \%}-\mathrm{GS}$ nanocomposite electrodes at $1 \mathrm{~A} \mathrm{~g}^{-1}$ and (b) $\mathrm{Ppy}_{1 \%}-\mathrm{DBSA}_{2 \%} / \mathrm{NiO}_{97 \%}$-GS@4 at different currents.

other hand, the lower specific capacitances of SC electrode at high scan rate are attributed to inaccessibility of electrolyte ions to some active surface sites. Even at a scan rate as high as $100 \mathrm{mV} \mathrm{s}{ }^{-1}$, the $\mathrm{Ppy}_{1 \%}-\mathrm{DBSA}_{2 \%} / \mathrm{NiO}_{97 \%}$ GS@4 electrode still achieves a Csp value as large as $359 \mathrm{~F} \mathrm{~g}^{-1}$. However, for $\mathrm{Ppy}_{1 \%}-\mathrm{DBSA}_{2 \%} / \mathrm{GS}$, Csp shows a severe decay of $73 \%$ with increasing scan rate from 5 to $100 \mathrm{mV} \mathrm{s}^{-1}$, and Csp is only $99.3 \mathrm{~F} \mathrm{~g}^{-1}$ at $100 \mathrm{mV} \mathrm{s}^{-1}$. 

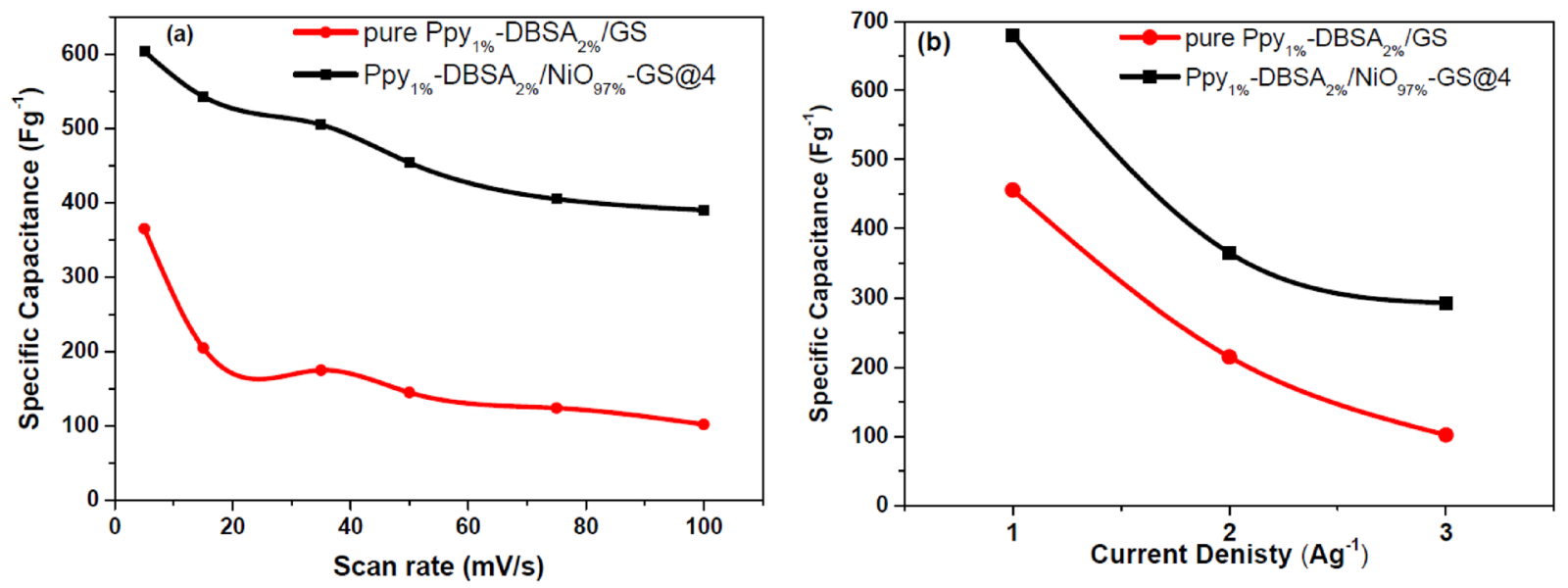

Figure 7. Specific capacitance at different scan rates (a) and specific capacitance at different current densities (b) for pure $\mathrm{Ppy}_{1 \%}-\mathrm{DBSA}_{2 \%} / \mathrm{GS}$ and $\mathrm{Ppy}_{1 \%}-\mathrm{DBSA}_{2 \%} / \mathrm{NiO}_{97 \%}-\mathrm{GS} @ 4$.

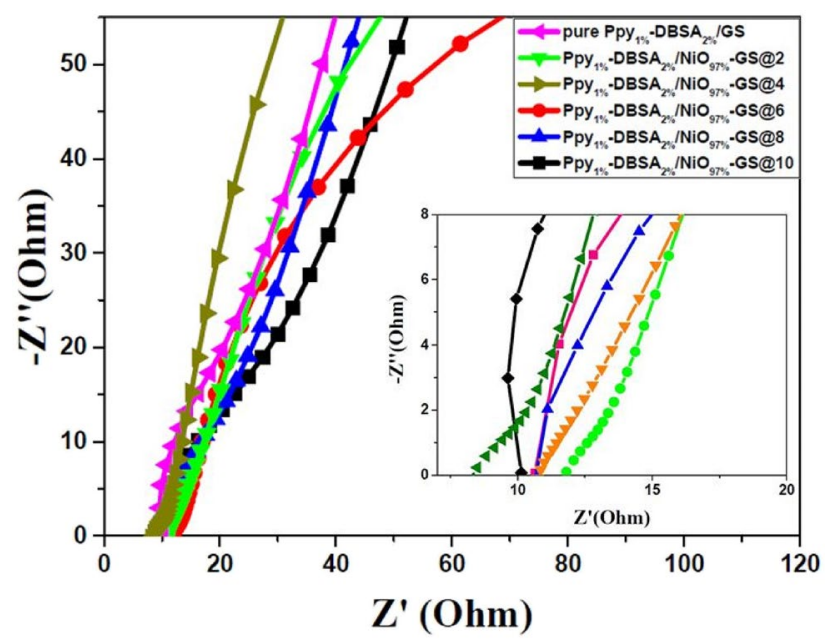

Figure 8. Nyquist plots (real impedance vs. imaginary impedance) of $\mathrm{PPy} / \mathrm{NiO}$ electrodes with different currents in the frequency range of $0.01 \mathrm{~Hz}$ to100 $\mathrm{kHz}$.

Figure $7 \mathrm{~b}$ illustrates the Csp values at various current densities from 1 to $3 \mathrm{~A} \mathrm{~g}^{-1}$. Csp values can be derived from GCD curves by using Eq. (2). The Ppy ${ }_{1 \%} \mathrm{DBSA}_{2 \%} / \mathrm{NiO}_{97 \%}$-GS@4 sample shows much larger Csp values at all current densities than $\mathrm{Ppy}_{1 \%}-\mathrm{DBSA}_{2 \%} / \mathrm{GS}$ with current densities increasing from 1 to $3 \mathrm{~A} \mathrm{~g}^{-1}$, which is in agreement with the results obtained from CV tests. The Csp of $\mathrm{Ppy}_{1 \%-} \mathrm{DBSA}_{2 \%} / \mathrm{NiO}_{97 \%}-\mathrm{GS} @ 4$ at $1 \mathrm{~A} \mathrm{~g}^{-1}$ is calculated to be $679 \mathrm{~F} \mathrm{~g}^{-1}$, which is much larger than the value of $456 \mathrm{~F} \mathrm{~g}^{-1}$ for $\mathrm{Ppy}_{1 \%}-\mathrm{DBSA}_{2 \%} / \mathrm{GS}$. Depending on these results calculated above, the capacitance utilization of $\mathrm{Ppy}_{1 \%-} \mathrm{DBSA}_{2 \%} / \mathrm{NiO}_{97 \%}-\mathrm{GS} @ 4$ is higher than that of $\mathrm{Ppy}_{1 \%}-\mathrm{DBSA}_{2 \%} / \mathrm{GS}$, indicating that a homogeneous distribution of PPy and $\mathrm{NiO}$ particles is beneficial for the transport of ions in full-gapped nanoparticle systems and for the increase of the PPy/electrolyte interfacial area. The decline of the specific capacitance at elevating current density is due to the inaccessibility of electroactive sites by the electrolyte ions.

Figure 8 shows the Nyquist plots for the Ppy/NiO nanocomposite electrodes synthesized electrochemically with different currents at the frequency range from 0.01 to $100 \mathrm{kHz}$ with amplitude of $5 \mathrm{mV}$. The long tails in the low-frequency region or the diffusion region are nearly vertical to the real axis. The intercept of the highfrequency curve in the real part reflects the equivalent series resistance (Rs) between the electrodes and electrolyte and equal to the summation of the Ohmic resistance of the electrolyte, the contact resistance, and the internal resistance of the material. From the inset of Fig. 8, the Ppy1\%-DBSA2\%/NiO97\%-GS@4 electrode possesses the smallest Rs $(8.1 \Omega$ ) compared to pure Ppy1\%-DBSA2\%/GS (10 $\Omega$ ), and Ppy1\%-DBSA2\%/NiO97\%-GS@6 exhibits the largest Rs (11.8 $\Omega$ ). However, no distinct semicircles are observed in the plots of all electrochemically prepared samples, indicating a small charge transfer resistance between the electrode and electrolyte and consequently the low effect of capacitive double layer. This resulted from the Ppy effect as a conducting polymer which proposed to have a redox behavior. Ppy1\%-DBSA2\%/NiO97\%-GS@4 and Ppy1\%-DBSA2\%/NiO97\%GS@6 have more vertical slopes demonstrating that they possess low diffusion resistances and contact resistances 


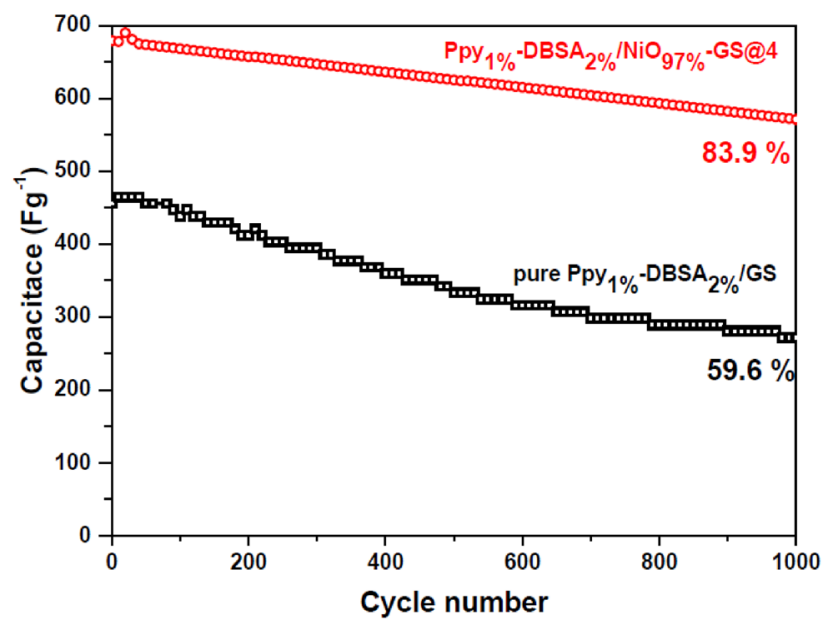

Figure 9. Cycling stability measurement of the pure $\mathrm{Ppy}_{1 \%}-\mathrm{DBSA}_{2 \%} / \mathrm{GS}$ and $\mathrm{Ppy}_{1 \%}-\mathrm{DBSA}_{2 \%} / \mathrm{NiO}_{97 \%}-\mathrm{GS} @ 4$ electrodes at $1 \mathrm{~A} \mathrm{~g}^{-1}$ for 1000 cycles.

between Ppy/NiO and the GS substrate ${ }^{42,43}$. These results are consistent and match well with the results obtained with SEM, CV, and GCD.

The cycle stability as an important parameter for supercapacitors for $\mathrm{Ppy}_{1 \%}-\mathrm{DBSA}_{2 \%} / \mathrm{NiO}_{97 \%}$-GS@4 and pure $\mathrm{Ppy}_{1 \%}-\mathrm{DBSA}_{2 \%} / \mathrm{GS}$ electrodes can be valued by their consecutive GCD at $1 \mathrm{Ag}^{-1}$ for $1000 \mathrm{cycles}$. As shown in Fig. 9 , the specific capacitance retentions are $83.9 \%$ and $59.6 \%$ of the initial value after 1000 cycles for Ppy $1 \%$ DBSA2\%/NiO97\%-GS@4 and pure Ppy1\%-DBSA2\%/GS, respectively. The Cs reduction resulted from a degradation of the PPy chains due to the excessive swelling and shrinking of the PPy polymer during the charge/discharge process. The clearly excellent long-term cycling stability of the Ppy1\%-DBSA2\%/NiO97\%-GS@4 composite may be attributed to the porous network gapped structure and good conductivity, which were favorable for charge transportation and electrolyte diffusion ${ }^{39}$. The presence of $\mathrm{NiO}$ nanoparticles not only enhances the capacitance value but also improves the cycling stability ${ }^{44}$.

\section{Conclusion}

The electrochemical results were improved for the chronopotentiometry deposited Ppy/NiO electrode at different currents onto the graphite sheet compared with the pristine Ppy electrode. It was found that the Ppy ${ }_{1 \%}-\mathrm{DBSA}_{2 \%} /$ $\mathrm{NiO}_{97 \%}$-GS@4 electrode demonstrated a high specific capacitance of $679 \mathrm{Fg}^{-1}$ at a current density of $1 \mathrm{Ag}^{-1}$ and capacitance retention of $83.9 \%$ of its initial capacitance after 1000 cycles at $1 \mathrm{Ag}^{-1}$. The high electrochemical performance of $\mathrm{Ppy}_{1 \%}-\mathrm{DBSA}_{2 \%} / \mathrm{NiO}_{97 \%}$-GS@4 was due to the synergistic effect of $\mathrm{NiO}$ and Ppy, where a uniform porous network-like structure made the electrolyte ions more easily accessible for Faradic reactions.

Received: 9 September 2021; Accepted: 21 February 2022

Published online: 04 March 2022

\section{References}

1. Moustafa, E. et al. Fabrication of high yield photoluminescent quantized graphene nanodiscs for supercapacitor devices. ACS Omega https://doi.org/10.1021/acsomega.1c02277 (2021).

2. Sun, C., Li, X., Cai, Z. \& Ge, F. Carbonized cotton fabric in situ electrodeposition polypyrrole as high-performance flexible electrode for wearable supercapacitor. Electrochim. Acta 296, 617-626 (2019).

3. Abdel-Fattah, T. M., Ebrahim, S., Soliman, M. \& Hafez, M. Dye-sensitized solar cells based on polyaniline-single wall carbon nanotubes composite. ECS J. Solid State Sci. Technol. 2, 6 (2013).

4. Jung, H. K. et al. Au-incorporated $\mathrm{NiO}$ nanocomposite thin films as electrochromic electrodes for supercapacitors. Electrochim. Acta 330, 135203 (2020).

5. Ebrahim, S. M. Fabrication of Schottky diode based on Zn electrode and polyaniline doped with 2-acrylamido-2-methylpropane sulfonate sodium salt'. J. Polym. Res. 16, 481-487 (2009).

6. Ebrahim, S., Soliman, M., Anas, M., Hafez, M. \& Abdel-Fattah, T. M. Dye-sensitized solar cell based on polyaniline/multiwalled carbon nanotubes counter electrode. Int. J. Photoenergy 20, 20 (2013).

7. Li, X. \& Zhitomirsky, I. Electrodeposition of polypyrroleecarbon nanotube composites for electrochemical supercapacitors. J. Power Sources 221, 49e56 (2013).

8. Liu, Y. et al. Supercapacitor with high cycling stability through electrochemical deposition of metal-organic frameworks/polypyrrole positive electrode. Dalton Trans. 47, 13472-13478 (2018).

9. Yavuz, A., Ozdemir, N. \& Zengin, H. Polypyrrole-coated tape electrode for flexible supercapacitor applications. Int. J. Hydrog. Energy 45(38), 18876-18887 (2020).

10 Asen, P. \& Shahrokhian, S. A high performance supercapacitor based on graphene/polypyrrole/ $\mathrm{Cu}_{2} \mathrm{O}-\mathrm{Cu}(\mathrm{OH})_{2}$ ternary nanocomposite coated on nickel foam. J. Phys. Chem. 121(12), 6508-6519 (2017).

11. Chen, G.-F. et al. Polypyrrole shell@3D-Ni metal core structured electrodes for high-performance supercapacitors. Chem. Eur. J. 21, 4614-4621 (2015).

12. Ge, J. et al. Z-scheme heterojunction based on $\mathrm{NiWO}_{4} / \mathrm{WO}_{3}$ microspheres with enhanced photocatalytic performance under visible light. Dalton Trans. 50, 13801-13814 (2021). 
13. Wang, C. et al. Facile construction of novel organic-inorganic tetra (4-carboxyphenyl) porphyrin/ $\mathrm{Bi} 2 \mathrm{MoO}_{6}$ heterojunction for tetracycline degradation: Performance, degradation pathways, intermediate toxicity analysis and mechanism insight. J. Colloid Interface Sci. 605, 727-740 (2022).

14. Feng, Yu. et al. Polypyrrole@ $\mathrm{MoO}_{3}$ /reductive graphite oxide nanocomposites as anode material for aqueous supercapacitors with high performance. Mater. Lett. 171, 104-107 (2016).

15. Feng, Y., Pang, L. \& Wang, H.-X. Preparation of mulberry-like $\mathrm{RuO}_{2}$ electrode material for supercapacitors. Rare Metal. 40(2), 440-447 (2021).

16 Kunwar, R. et al. Transformation of supercapacitive charge storage behaviour in a multi elemental spinel $\mathrm{CuMn}_{2} \mathrm{O}_{4}$ nanofbers with alkaline and neutral electrolytes. Adv. Fiber Mater. 20, 20 (2021).

17 Inamdar, H. K., Sridhar, B. C., Sasikal, M. \& Ambika Prasad, M. V. N. Structural and optical properties of polypyrrole/NiO doped nanocomposites. J. Nanosci. Tech. 4(3), 400-401 (2018).

18. Agobi, A. U., Louis, H., Magu, T. O. \& Dass, P. M. A review on conducting polymers-based composites for energy storage application T. J. Chem. Rev. 1, 19-34 (2019).

19. Ren, G., Li, S., Fan, Z., Hoque, M. \& Fan, Z. Ultrahigh-rate supercapacitors with large capacitance based on edge oriented graphene coated carbonized cellulous paper as flexible freestanding electrodes. J. Power Sources 325, 152 (2016).

20. Liu, D. et al. Porous nitrogen-doped graphene for high energy density supercapacitors in an ionic liquid electrolyte. J. Solid State Electrochem. 21, 759 (2017).

21. Liu, A., Li, C., Bai, H. \& Shi, G. Electrochemical deposition of polypyrrole/sulfonated graphene composite films. J. Phys. Chem. C 114(51), 22783-22789 (2010).

22. Woo, T.-G., Park, I.-S. \& Seol, K.-W. Effects of various metal seed layers on the surface morphology and structural composition of the electroplated copper layer. Metal. Mater. Int. 15(2), 293-297 (2009).

23 Alexandra, B., Marcu, M., Alexandrescu, E. \& Anghel, E. M. "Electrochemical deposition and characterization of polyppyrrole coatings doped with nickel cobalt oxide for environmental applications. J. Solid State Electrochem. 18(10), 2661-2671 (2014).

24 Wang, J. C. Y. et al. Facile co-electrodeposition method for high-performance supercapacitor based on reduced graphene oxide/ polypyrrole composite film. ACS Appl. Mater. Interfaces 9, 19831-19842 (2017).

25 Vijeth, H., Ashokkumar, S. P., Yesappa, L., Vandana, M. \& Devendrappa, H. Hybrid core-shell nanostructure made of chitosan incorporated polypyrrole nanotubes decorated with $\mathrm{NiO}$ for all-solid-state symmetric supercapacitor application. Electrochim. Acta 354(10), $136651(2020)$.

26. Hosseinian, M., Darzi, G. N. \& Rahimpour, A. A novel bioelectrochemical sensor based on immobilized urease on the surface of nickel oxide nanoparticle and polypyrrole composite modified Pt electrode. Electroanalysis 31, 2530-2537 (2019).

27 Tyagi, M., Tomar, M. \& Gupta, V. NiO nanoparticle-based urea biosensor. Biosens. Bioelectron. 41, 110-115 (2013).

28. Nalage, S. R., Navale, S. T. \& Patil, V. B. Polypyrrole-NiO hybrid nanocomposite: Structural, morphological, optical and electrical transport studies. Measurement 46, 3268-3275 (2013).

29 Pattanayak, P., Papiya, F., Kumar, V. \& Pramanikd, N. PP Kundu", Deposition of Ni-NiO nanoparticles on the reduced graphene oxide filled polypyrrole: evaluation as cathode catalyst in microbial fuel cells. Sustain. Energy Fuels 3, 1808-1826 (2019).

30. Zhang, J., Wu, C., Li, T., Xie, C. \& Zeng, D. Highly sensitive and ultralow detection limit of room-temperature NO2 sensors using in situ growth of PPy on mesoporous NiO nanosheets. Organ. Electron. 77, 105504 (2020).

31 Sonavane, A. C., Inamdar, A. I., Dalavi, D. S., Deshmukh, H. P. \& Patil, P. S. Simple and rapid synthesis of NiO/PPy thin films with improved electrochromic performance. Electrochim. Acta 55, 2344-2351 (2010).

32. Ebrahim, S. M., ElLatif, A. \& Soliman, M. Blend of nylon 6 and polyaniline doped with sulfanilic acid and its schottky diode. High Performa. Polym. 22, 377-391 (2010).

33. Liu, J.-H. et al. Facile construction of 3D porous carbon nanotubes/polypyrrole and reduced graphene oxide on carbon nanotube fiber for high performance asymmetric supercapacitors. Electrochim. Acta 314, 9-19 (2019).

34. Elessawy, N. A., El Nady, J., Wazeer, W. \& Kashyout, A. B. Development of high-performance supercapacitor based on a novel controllable green synthesis for 3D nitrogen doped graphene. Sci. Rep. 9, 1129 (2019).

35. Cai, Y. et al. Electrochemical self-assembled core/shell PEDOT@MoS 2 composite with ultra-high areal capacitance for supercapacitor. Electrochim. Acta 370, 137791 (2021).

36 Sidhu, N. K. \& Rastogi, A. C. Vertically aligned $\mathrm{ZnO}$ nanorod core-polypyrrole conducting polymer sheath and nanotube arrays for electrochemical supercapacitor energy storage. Nanosc. Res. Lett. 9, 453 (2014).

37. Wang, Y. et al. Mesoporous transition metal oxides for supercapacitors. Nanomaterials 5, 1667-1689 (2015).

38. Liu, H. et al. Facile synthesis of polypyrrole nanofiber (PPyNF)/NiOx composites by a microwave method and application in supercapacitors. RSC Adv. 9, 6890 (2019).

39 Majid, S. R. Effects of electrodeposition mode and deposition cycle on the electrochemical performance of $\mathrm{MnO} 2-\mathrm{NiO}$ composite electrodes for high-energy-density supercapacitors. PLoS One 11(5), e0154566 (2016).

40. Ji, W. et al. Polypyrrole encapsulation on flower-like porous $\mathrm{NiO}$ for advanced high-performance supercapacitors. Chem. Commun. 51, 7669 (2015).

41. Cheng, J. et al. High-performance supercapacitor applications of nionanoparticle decorated millimeter-long vertically aligned carbon nanotube arrays via an effective supercritical $\mathrm{CO}_{2}$-assisted method. Adv. Funct. Mater. 25, 7381-7391 (2015).

42. Prakash, D. \& Manivannan, S. Unusual battery type pseudocapacitive behaviour of graphene oxynitride electrode: High energy solid-state asymmetric supercapacitor. J. Alloys Compd. 854, 156853 (2021).

43 Abdah, M. A. A. M., Razali, N. S. M., Lim, P. T., Kulandaivalu, S. \& Sulaiman, Y. One-step potentiostatic electrodeposition of polypyrrole/graphene oxide/multi-walled carbon nanotubes ternary nanocomposite for supercapacitor. Mater. Chem. Phys. 219, $120-128$ (2018).

44. Zou, K.-M. et al. Preparation of a NiAl-oxide@Polypyrrole composite for high-performance supercapacitors. Chem. Asian J. 14, 4337-4344 (2019).

\section{Author contributions}

J.E.N.* experimental work, interpretation of the data and wrote the main manuscript text. A.S. share in the characterization and explaining the results of characterization. M.K. share in the characterization and explaining the results of characterization. S.E. supervised and revised the manuscript. A.M.E. share the writing of manuscript , prepared the figures. M.A. share in the characterization and explaining the results of characterization.

\section{Funding}

Open access funding provided by The Science, Technology \& Innovation Funding Authority (STDF) in cooperation with The Egyptian Knowledge Bank (EKB).

\section{Competing interests}

The authors declare no competing interests. 


\section{Additional information}

Correspondence and requests for materials should be addressed to J.E.N.

Reprints and permissions information is available at www.nature.com/reprints.

Publisher's note Springer Nature remains neutral with regard to jurisdictional claims in published maps and institutional affiliations.

(c) (1) Open Access This article is licensed under a Creative Commons Attribution 4.0 International License, which permits use, sharing, adaptation, distribution and reproduction in any medium or format, as long as you give appropriate credit to the original author(s) and the source, provide a link to the Creative Commons licence, and indicate if changes were made. The images or other third party material in this article are included in the article's Creative Commons licence, unless indicated otherwise in a credit line to the material. If material is not included in the article's Creative Commons licence and your intended use is not permitted by statutory regulation or exceeds the permitted use, you will need to obtain permission directly from the copyright holder. To view a copy of this licence, visit http://creativecommons.org/licenses/by/4.0/.

(C) The Author(s) 2022 